\title{
Disposal of Mining Waste: Classification and International Recycling Experience
}

\author{
Mourad Samir ${ }^{1, *}$, Faruz Alama ${ }^{1}$, Paul Buysse ${ }^{2}$, Tomas van Nylen ${ }^{2}$, and Oleg Ostanin ${ }^{3}$ \\ ${ }^{1}$ Lebanese International University, 146404 Mazraa, Mouseitbeh, Lebanon \\ ${ }^{2}$ University of Antwerp, 2000 Prinsstraat 13, Antwerpe, Belgium \\ ${ }^{3}$ T.F. Gorbachev Kuzbass State Technical University, Surveying and Geology Department, 650000 \\ Vesennya st. 28, Kemerovo, Russian Federation
}

\begin{abstract}
The main directions of mining and industrial wastes' utilization are the production of building materials, their use in the construction industry without additional processing, and also the production of metals from metal-containing raw materials. It should be noted that current waste is preferable for the production of building materials, since they preserve the primary physical and mechanical properties and chemical composition and, moreover, can reach the consumer bypassing all other steps that are mandatory for waste consolidated (transportation, storage, etc.). For the production of building materials, not less than $30 \%$ of overburden and refinement tailings are suitable, almost all metallurgical and fuel slags, waste products of fertilizers and building materials. Even larger amounts of waste can be used for various laying and burial works (construction of road bases and dams, filling of worked out areas, leveling of the relief).
\end{abstract}

\section{Introduction}

More than $95 \%$ of metallurgical slags, especially valuable for the construction industry, are located in the Urals, North, East-Siberian and West-Siberian economic regions. The main volumes of waste rock overburden are concentrated in the same areas, and taking into account the Far East, they account for about $90 \%$ of the total [1-2].

In the mineral and raw materials complex in general and in the metallurgical sector, in particular, there was a contradiction between the significant volumes of overburden, the low level of their use as building materials (no more than $1 \%$ of the total volume) and the high demand of the construction industry (up to 1.5 billion tons) in inert aggregates in the form of sand, gravel, gravel and other materials. In the national economy there is a situation when the construction industry is not connected with the mining industry and produces raw materials for the production of building materials in its own deposits, the number of which has exceeded 5 thousand [3-4]. This situation is due to two factors. On the one hand, prices for construction products are relatively low; on the other hand, significant transportation distances to the final consumer make the production of construction materials from overburden economically unprofitable due to the high transport tariffs. Nevertheless, according

\footnotetext{
* Corresponding author: info@liu.edu.lb
} 
to experts, about $20 \%$ of overburden is formed in the areas of building materials consumption. The creation of construction enterprises on the basis of waste from mining production increasing the depth of construction materials' processing will reduce the dependence of the delivery of construction products from transport without significant decrease of its economic efficiency.

The volumes of metal components in mining and industrial wastes are comparable with the reserves of large deposits. Wastes from non-ferrous metallurgy enterprises contain useful components in the following quantities, thousand tons: copper 7790, lead 980, zinc 9000, tin 540, nickel 2480, tungsten 129, molybdenum 4, lithium 97. About 5 thousand tons of alluvial gold contain dumping complexes of gold mines [4-5]. Metal useful components are also available in the waste of ferrous metallurgy, heat and power engineering, coal industry and even in construction materials waste (for example, gold in the clayey part of sand-processing waste).

\section{Materials and Methods}

The creation of scientific bases for estimating secondary mineral resources and solving practical problems of their use requires the development of a classification of these resources by the most significant features. Authors dealing with the problems of the use of secondary mineral resources offer different approaches to the selection of the most significant classification features.

The problem of classification, depending on specific characteristics, applied to wastes, was solved by classification, which covers the waste of 17 industries with the characteristics of properties and the possible area of their application: [5-7]

- on technological stages of formation;

- on the valuable components contained in the waste;

- on the degree of damage to the environment;

- on the possibility of their secondary involvement in production;

- on the costs necessary for their use.

It should be accepted that the extraction of minerals should be regarded as the first stage on the way of the transformation of the substance of nature into a product ready for consumption. The extraction of primary raw materials from local natural structures, in view of the complexity of the natural resources or their combination within these structures, is accompanied by the extraction of associated components, which constitute the first group of waste. Concurrently mined rocks are referred to the category of secondary raw materials.

Considering overburden as a source of resources, we should proceed from the fact that they have already been in the labor process and, thus, in this case it is the intermediate product in terms of utility and satisfaction of the need, which is identified with the raw materials.

The specificity of this waste group is determined by the fact that their output (quantity) is unambiguously (functionally) unrelated to the volume of extraction or processing of primary raw materials, but depends on the mining and geological conditions of deposits [8].

In the second group of waste there are two of their types, although they do not always appear in an isolated form:

- resources lost during production: flowing with water discharge, gases or made not suitable as a result of depletion, dilution, mixing. In a number of cases, their regeneration (recovery) and reuse within the framework of the initial production are most expedient. These waste products are called returnable;

- wastes generated as a result of physical and chemical processing of raw materials and auxiliary materials. 
Some researches divide waste by industries into waste of electricity, fuel industry, ferrous and non-ferrous metallurgy, chemical industry, and within these groups - into waste by name of enterprises and installations. When considering specific industrial waste groups, their classification is limited to the technological stages of formation. M.P. Pedan classifies wastes by mining industries, and within them - by technological stages of formation, types of ores, fractions, etc.

The analysis of publications shows that the main features of production wastes classification are the industry of their formation, the aggregate state, and the technological stages of development.

Classification of technogenic resources is based on two groups of resources and their following characteristics:

- natural mineral raw materials - industrial type of natural deposit, industrial types and grades of ores, a list of associated useful and harmful impurities;

- industrial and technological types of technogenic resources - technological process, in the course of which technogenic raw materials, storage type, degree of study, geotechnical condition of the foundation, name of technogenic raw materials (waste, out of balance ores), physical-chemical composition, content of useful components, degree of oxidation of minerals of ores, direction of use.

M.E. Kyabbi for estimating the accumulation and use of mining waste proposes to classify them on grounds of the following main features [9]:

- the field of formation in the mining industry;

- the stages of production cycle;

- accumulation time;

- the degree of study:

- the application sphere;

- the application effectiveness.

The proposed classification has a sufficient number of features, but the qualitative component within the classification blocks is insufficient. This is especially true for such classification characteristics as the application sphere and the degree of study.

A very significant step forward in the development of wastes classification in mining and industrial production is the classification of V.V. Chaynikova and E.L. Goldman [10]. Authors, subdividing the waste according to the sectoral criteria, introduce such important classification criteria as the resource value of waste, the impact on human health. Some lack of the classification, in our opinion, is not completely correct division into classes and types, to which certain types of waste are referred in accordance with grouping features.

As a result of the analysis of existing classifications, taking into account their continuity, the author developed a classification of wastes by the example of extraction and enrichment of non-ferrous metallurgy wastes as the most "wasteful" branch, even among the branches of mining industry. Among the methods used by the author, it is necessary to distinguish the method of limiting the individual groups and types of waste and the method of singling out one major classification feature with the identification of sub-signs.

Peculiarity of waste as a raw material resource consists in a variety of ways of their utilization. The most typical are the following:

1. Immediate replacement of primary raw materials with waste (without special processing), determined by the equivalence of some of their technological properties (primarily overburden and incidentally mined rocks that directly correspond to natural types of mineral raw materials that have their own mono-production).

2. The use of waste in place of feedstock, provided they are additionally (specially) processed. The resulting secondary raw materials are then used as material resources in any production sector. This most common type of recycling includes waste of residual type, regeneration and other processing of which also allows obtaining secondary raw materials. 


\section{Results and Discussion}

For a more complete assessment of the importance of mining and industrial waste in various sectors of economy, an analysis of foreign experience is needed. In economically developed countries, considerable experience in resource conservation in general and the use of technogenic resources in particular has been accumulated. For example, in the USA, as early as 1980, the law "On Research and Development in the Field of Provision with Raw Materials" was adopted, which envisages the combination of resource saving and environmental protection objectives based on the application of low- and non-waste technologies; concentration of scientific and investment efforts for the creation and application of resource-saving technologies; the reduction of economy dependence on imported resources; distribution of previously developed advanced technologies; development and application of the latest technologies, materials and technology.

The USA, Japan and most countries of Western Europe adhere to the principles of mineral resource conservation, consumer orientation to cheaper foreign sources of non-ferrous, rare and precious metals, purposeful creation of large strategic reserves in their economic policies. The United States pays particular attention to the creation of strategic reserves. The list of strategic stocks of components in the United States consists of 107 items, including metals, ore concentrates, fossil fuels (91 products). Tin, tungsten, manganese, chromium, antimony, rare metals, uranium, platinum, diamonds, oil, gas and others are referred to the strategic reserves in the United States. Material cost of these reserves is estimated at 19.2 billion. A significant share of non-ferrous metals production in the United States belongs to their production of secondary resources. So, in 2002 the share of some types of secondary raw materials in total consumption was characterized by the following data (\%): copper, 57.9, 28, nickel, cobalt 12, tungsten 27 . In the structure of consumption of most non-ferrous metals in the United States the proportion of secondary raw materials in the past 15 years increased more than 5 times [4].

A very significant reserve of additional production of non-ferrous and precious metals is the use of secondary mineral resources, primarily tailings and off-balance ores. Significant experience of such use has been accumulated in the USA, Canada, Japan, Great Britain, Germany, Australia, and South Africa. Thus, studies conducted by the US Mining Department show that concentrates containing 2.2 to $13 \%$ of copper can be obtained from the tailings of enrichment (current yield and old-age) in a number of concentrating plants when extracting from 15 to $65 \%$ by the flotation method and leaching. Before enrichment, tails are usually classified in hydro-cyclones with the release of sand and slurry fractions. At present, a hydrometallurgical facility with a capacity of 60,000 tons of tails per day, containing 0.21 percent of copper, has been put into operation in the USA at the factory of Morenci (Arizona). The technological scheme includes agitation leaching, thickening, washing and neutralization of residues from leaching, precipitation of copper from the solution. In the state of Michigan, tailings are processed by flotation with an average content of $0.3 \%$. In Lark (Utah), the volume of accumulated tailings from the processing of copper ore is 5 million tons with a copper content of $0.37 \%$. At present, the processing of these wastes is carried out by the flotation method, and the tailing dumps are extracted hydraulically. At the copper mining and processing plant "Butte" (Kansas), heap leaching of copper from old tailings is carried out. At the plant "ArtyrandMagna" there are installations for copper extraction from tailings with the capacity of more than 100 thousand tons per day with the production of concentrate containing $20 \%$ of copper [5].

In Canada, the Cowper Mountain factory has developed a technology for processing lean tailings by leaching. In Australia, a plant for flotation of tails from dumps containing $0.5-1.5 \%$ of copper is currently operating at the Kadina plant. As a result of the flotation process, a copper concentrate containing $25 \%$ of copper is produced. In Japan, at the Hita- 
chi factory, tailings of dumps accumulated during 5 years of operation of the factory and containing $0.36 \%$ of copper, $0.35 \%$ of zinc and $5.46 \%$ of sulfur are processed. The processing of tailings is carried out by flotation using sulfuric acid [5].

Abroad great attention is paid to the use of waste enrichment for the production of building materials. In Germany, the production of plumbic-sand bricks, blocks and aerated concrete products with the use of large and fine fraction of tailings of enrichment is established at the plumbic-zinc plant "August Victoria". The studies have been carried out and the possibility of producing porous slate and light concrete from tailings with the introduction of appropriate additives has been established. The US Mining Department has developed a method for making bricks from tails containing $65-76 \%$ quartz and asbestos fines. In the UK, the silicate tails of non-ferrous metallurgy plants are used to produce building blocks from which "heating" walls are made. The components of the "heating walls" are finely ground silicate tails and a plastic substance.

Recycling of dump tailings is widespread in South Africa. The reserves of coarsegrained tailings with a significant content of the main valuable components in them in the dumps of the enrichment plants of this country reach 230 million tons. The National Institute of Metallurgy is improving the efficiency of tailings processing technology. Currently, in South Africa, the tailings are processed according to traditional schemes with the refining of the concentrate, including gravity or flotation.

In general, an analysis of the international recycling experience made it possible to draw the following conclusions:

1. A generalizing criterion distinguishing secondary material resources from waste and secondary mineral resources from mining waste is the scientific and technical possibility of using the latter at a given time. Under secondary mineral resources, it is necessary to understand a part of the mining and industrial waste generated as a result of irrational use of mineral resources, which can be reused at this stage of science and technology development. In accordance with the adopted definition, secondary mineral resources are an integral part of the natural resource potential. The terms secondary mineral resources and technogenic mineral resources can act as synonyms in the aspect of this study.

2. For the classification of mining and industrial waste, a set of mining technological and organizational-economic characteristics is required. As the most important classification criteria, the author suggests the direction of using secondary mineral resources.

3. The volume of secondary mineral resources currently used in the world is quite low, absolutely inconsistent with their economic potential and is caused by a complex of reasons, among which there are imperfections in the legislative framework, high risk of nonreturn of capital in mining sectors, weak incentives for the involvement of waste in the production process, the imperfection of their accounting, insufficient methodological justification of the criteria for their evaluation.

\section{Conclusion}

It is obvious that the utilization of not all technogenic resources as mineral raw materials will be economically viable either in connection with the lack of demand or because of low profitability. In this regard, for each man-made facility, all possible options for disposal from various positions should be considered, and environmental ones are especially important. This is due in particular to the fact that mining waste is an intensive source of impact on all spheres of the environment and on human health. In the area of their impact, the disease incidence of the population is significantly increased, life expectancy is shortened. Mining and industrial waste only in the Sverdlovsk region occupy areas of tens of square kilometers, while the area of groundwater contamination around the tailings and sludge dumps is tens times larger than the storage area, and the size of the geochemical soil con- 
tamination zone around the mining and metallurgical plants exceeds the dimensions of their land allotment in 30-40 times. The conducted studies show that the active surface of technogenic objects per unit volume is 100-1000 times higher than that of rocks. Therefore, the impact of techno-genetic objects leads to contamination of both groundwater and large rivers, which are sources of water supply.

Analysis of the international experience of recycling of man-made raw materials indicates that they can be significant sources of obtaining various useful components. The production costs can be much lower than in the processing of raw materials. Nevertheless, at present the volume of secondary mineral resources is very low: in Russia it was about $1 \%$ of the accumulated mining and industrial waste in 2005.

\section{References}

1. O. Litvin, M. Tyulenev, S. Zhironkin, S. Prokopenko, Acta Montanistica Slovaca, 22:2, 146-152 (2017)

2. M. Tyulenev, Y. Lesin, E. Tyuleneva, E. Murko, E3S Web of Conferences, 15, 02003 (2017)

3. M. Tyulenev, S. Zhironkin, E. Tyuleneva, A. Abay, S. Anyona, M. Hellmer, Coal International, 265:3, 30-34 (2017)

4. M. Tyulenev, Y. Lesin, O. Litvin, E. Maliukhina, A. Abay, E3S Web of Conferences, 21, 02019 (2017)

5. V. Kolesnikov, O. Litvin, J. Janočko, A. Efremenkov, E3S Web of Conferences, 21, 01031 (2017)

6. S.N. D'yakov, A.V. Papin, A.V. Nevedrov, E.V. Zhbyr', Coke and Chemistry, 55(10), 363 (2012)

7. T. Gvozdkova, S. Markov, N. Demirel, S. Anyona, E3S Web of Conferences 21, 01024 (2017)

8. S. Markov, V. Martyanov, E. Preis, A. Abay, E3S Web of Conferences 21, 01021 (2017)

9. M. E. Kyabbi, Mining waste classification (Nedra, Moscow, 2002)

10. V.V. Chaynikova, E.L. Goldman, The utilization of mining waste (SPMI, Saint Petersburg, 2002) 